\title{
PENGARUH PERILAKU KOMUNIKASI TERHADAP SIKAP DAN ADOPSI TEKNOLOGI BUDIDAYA BAWANG MERAH DI LAHAN PASIR PANTAI KECAMATAN SANDEN KABUPATEN BANTUL
}

\section{The Influence of Communication Behaviour Toward the Attitude and Adoption on Technology of Onion Cultivation in Sandy Coastal Land of Sanden Subdistrict Bantul District}

\author{
Wahyu Aji Sasongko ${ }^{1)}$, Roso Witjaksono ${ }^{2)}$, Harsoyo ${ }^{2)}$ \\ 1) Jurusan Sosial Ekonomi Pertanian Fakultas Pertanian Universitas Gadjah Mada \\ ${ }^{2)}$ Fakultas Pertanian Universitas Gadjah Mada
}

\begin{abstract}
This research was conducted in Sanden subdistrict Bantul district with the purpose of finding out: 1) the communication behavior of onion farmers, 2) factors affecting communication behaviour, 3) factors affecting farmer's attitude, and 4) the influence of communication behavior, attitude, and other factors, toward technology adoption of onion cultivation.

The method used in this research was descriptive approach by survey technique. The sampling of village and farming groups were done purposively, while the sampling of respondent farmers was done randomly. The number of total sample was 60 farmers consisted of 30 farmers from Manunggal Farming Group, Srigading Village, and 30 farmers from Karang Rejo Farming Group, Gadingharjo Village. The analysis methods used were proportion test and multiple linier regression analysis.

The result of this research showed that farmer's communication behavior belonged to low category. The credibility of communication media positively affected toward farmer's communication behavior, while education, land size, and motivation didn't have significant affect. Communication behavior, motivation, dan education positively affected toward farmer's attitude, while land size didn't have significant affect. Farmer's attitude positively affected toward technology adoption of onion cultivation, communication behavior, motivation, education, dan land size didn't have significant affect. Communication behavior affected toward attitude and furthermore attitude affected toward technology adoption of onion at sandy coastal land.
\end{abstract}

Keywords: adoption, attitude, communication behavior, onion, sandy coastal land, Bantul.

\section{INTISARI}

Penelitian ini dilakukan di Kecamatan Sanden Kabupaten Bantul dengan tujuan mengetahui: 1) perilaku komunikasi petani bawang merah lahan pasir pantai, 2) faktor-faktor yang mempengaruhi perilaku komunikasi, 3) faktor-faktor yang dapat mempengaruhi sikap petani, serta 4) pengaruh perilaku komunikasi, sikap, dan faktorfaktor lain terhadap adopsi teknologi budidaya bawang merah.

Metode yang digunakan dalam penelitian ini adalah metode deskriptif dengan teknik survei. Pengambilan sampel desa dan kelompok tani dilakukan secara purposif, sedangkan pengambilan sampel petani responden dengan acak sederhana. Total sampel berjumlah 60 petani yaitu 30 petani dari Kelompok Tani Manunggal, Desa Srigading dan 30 petani dari Kelompok Tani Karang Rejo, Desa Gadingharjo. Metode analisis yang digunakan adalah uji proporsi dan analisis regresi linier berganda.

Hasil penelitian menunjukkan bahwa perilaku komunikasi petani termasuk kategori rendah. Kredibilitas media komunikasi berpengaruh positif terhadap perilaku komunikasi petani, sedangkan pendidikan, luas lahan, dan motivasi tidak berpengaruh nyata terhadap perilaku komunikasi petani. Perilaku komunikasi, motivasi, dan pendidikan berpengaruh positif terhadap sikap petani, sedangkan luas lahan tidak berpengaruh nyata terhadap sikap petani. Sikap petani berpengaruh positif terhadap adopsi teknologi budidaya bawang merah. Perilaku komunikasi, motivasi, pendidikan, dan luas lahan tidak berpengaruh nyata terhadap adopsi teknologi budidaya bawang merah. Perilaku komunikasi mempengaruhi sikap dan selanjutnya sikap mempengaruhi adopsi teknologi bawang merah lahan pasir pantai

Kata kunci: Perilaku komunikasi, sikap, adopsi, bawang merah, lahan pasir pantai, Bantul.

\section{PENDAHULUAN}

\section{A. Latar Belakang}

Transformasi lahan pasir pantai marginal menjadi lahan pertanian produktif di Kecamatan Sanden Kabupaten Bantul menjadikan lokasi tersebut kini memiliki daya tarik dan nilai lebih. Keberadaan lahan pasir pantai yang dulu dipandang sebelah mata kini telah mampu diubah menjadi lahan pertanian yang mampu menghasilkan produk komoditas pertanian yang 
bernilai ekonomi tinggi, yaitu bawang merah dan cabai merah.

Lahan pasir pantai memerlukan perlakuan khusus yang berbeda dengan lahan sawah pada umumnya. Berbagai macam teknologi mulai dari cara pengolahan lahan, pemupukan, pengairan, dan teknik budidaya lainnya telah dirancang sedemikian rupa sehingga lahan pasir pantai yang semula merupakan lahan marginal tersebut dapat ditanami komoditas pertanian.

Agribisnis bawang merah di lahan pasir pantai memiliki potensi yang cukup besar. Sebagai komoditas hortikultura, bawang merah memiliki nilai ekonomi tinggi. Bawang merah mempunyai prospek yang cukup baik untuk meningkatkan pendapatan petani dan mendorong perkembangan agribisnis di DIY. Menurut Kepala Dinas Pertanian DIY, produksi bawang merah di DIY dalam setahun mencapai 12 ribu ton. Sementara kebutuhan bawang merah penduduk di DIY hanya sekitar 10 ribu ton per tahun. Dengan demikian produksi bawang merah di DIY sebetulnya sudah surplus (Rachman, 2013). Menurut data BPS Bantul (2012), luas panen komoditas bawang merah di Kecamatan Sanden dapat dikatakan relatif besar yaitu mencapai 612 hektar dengan rata-rata produksi $126,85 \mathrm{kw} / \mathrm{ha}$ dan total produksi $77.663 \mathrm{kw}$ atau terbesar di Kabupaten Bantul. Hal tersebut tentunya merupakan potensi agribisnis yang sangat baik mengingat akhir-akhir ini dalam skala nasional, komoditas bawang merah tengah mendapat sorotan karena ketersediaannya cenderung menurun yang berakibat pada lonjakan harga yang sangat tinggi.

Upaya peningkatan produktivitas bawang merah di lahan marginal tersebut dilakukan dengan memperkenalkan teknologi baru, baik teknologi lokal setempat maupun teknologi yang dihasilkan oleh lembaga penelitian. Teknologi budidaya bawang merah terdiseminasi atau tersebar melalui proses komunikasi, baik melalui media komunikasi massa, kelompok, maupun individu atau interpersonal. Petani tidak dapat secara langsung menerima atau mengadopsi suatu inovasi. Inovasi pertanian akan dapat diadopsi oleh individu maupun kelompok-kelompok dalam masyarakat apabila masyarakat memiliki intensitas interaksi dan kualitas komunikasi yang baik. Rogers (1995) mendefinisikan komunikasi sebagai proses dimana pelaku komunikasi membuat dan menyebarkan informasi dengan orang lain untuk mencapai pemahaman yang sama. Komunikasi secara efektif dapat mendorong kelancaran proses difusi sehingga suatu teknologi dapat diadopsi dengan baik oleh masyarakat. Intensitas interaksi baik melalui media interpersonal, media kelompok, maupun media massa akan mendukung dan memudahkan alur diseminasi penyebaran inovasi sehingga suatu teknologi baru dapat diterima dan diaplikasikan dengan baik oleh pengguna teknologi.

\section{B. Tujuan}

1. Mengetahui perilaku komunikasi petani dalam adopsi teknologi budidaya bawang merah di Kecamatan Sanden Kabupaten Bantul.

2. Mengetahui faktor-faktor yang mempengaruhi perilaku komunikasi petani lahan pasir pantai dalam adopsi teknologi budidaya bawang merah di Kecamatan Sanden Kabupaten Bantul.

3. Mengetahui pengaruh perilaku komunikasi dan faktor-faktor lain terhadap sikap petani bawang merah di Kecamatan Sanden Kabupaten Bantul.

4. Mengetahui pengaruh perilaku komunikasi, sikap, dan faktor-faktor lain terhadap adopsi teknologi budidaya bawang merah di Kecamatan Sanden Kabupaten Bantul.

\section{Tinjauan Pustaka}

\section{Perilaku Komunikasi}

Perilaku adalah tindakan yang
mengimplementasikan pengetahuan dan sikap yang telah terbentuk pada diri manusia. Hal ini juga berkaitan dengan norma yang berlaku pada masyarakat (Irmasari, 2013).

Menurut Rogers dan Shoemaker dalam Witjaksono (1990), perilaku komunikasi petani selalu berkaitan dengan usaha memperoleh informasi pertanian sebagai bahan pertimbangan untuk mengambil keputusan. 


\section{Faktor-Faktor yang Mempengaruhi Perilaku Komunikasi}

\section{a. Kredibilitas Media Komunikasi}

Kredibilitas adalah seperangkat persepsi yang dimiliki komunikan tentang sifatsifat komunikator. Karena kredibilitas itu masalah persepsi, maka kredibilitas berubah-ubah tergantung pada pelaku persepsi (komunikan), topik yang dibahas, dan situasi (Anonim, 2008).

Persepsi keandalan dan kepercayaan terhadap informasi secara signifikan dapat mempengaruhi pemilihan dan penggunaan sumber-sumber informasi. Secara khusus, pentingnya kriteria ini ditekankan ketika pencari informasi menemukan informasi yang bertentangan. Dalam situasi ini, mereka harus menilai kredibilitas dan sumber teori dari alternatif yang ada (Savolainen, 2007).

\section{b. Pendidikan}

Prayitnohadi dalam Witjaksono (1990) mengungkapkan bahwa semakin tinggi pendidikan formal petani akan semakin tinggi pula kemampuannya untuk menerima, menyaring, dan menerapkan inovasi teknologi yang diperkenalkan. Berdasarkan hasil penelitian Indarwati (2005) diketahui bahwa semakin tinggi tingkat pendidikannya, petani semakin aktif dalam perilaku komunikasi.

\section{c. Motivasi}

Proses komunikasi merupakan hal yang penting dalam rangka pemenuhan kebutuhan- kebutuhan tersebut. Perilaku komunikasi merupakan salah satu indikator eksistensi individu dalam masyarakat. Begitu pula untuk memenuhi kebutuhan akan relatedness, individu akan menjalin komunikasi interaktif dengan orang lain dan dalam pemenuhan kebutuhan untuk tumbuh dan berkembang individu juga membutuhkan suatu proses komunikasi interaktif dengan orang lain dan lingkungannya.

Teori motivasi yang dikembangkan oleh Alderfer dalam Siagian (2004) yaitu teori ERG:

\section{Existence}

Mempertahankan eksistensi seseorang merupakan kebutuhan yang sangat mendasar. Mempertahankan eksistensi secara terhormat itu berarti antara lain terpenuhinya kebutuhan dasar. Bila menggunakan klasifikasi Maslow berarti terpenuhinya kebutuhan primer dan rasa aman.

\section{Relatedness}

Kebutuhan akan relatedness tercermin pada sifat dasar manusia sebagai insan sosial. Setiap orang ingin mengaitkan keberadaannya dengan orang lain dan dengan lingkungannya. Bila dibandingkan dengan klasifikasi Maslow kebutuhan relatedness identik dengan kebutuhan sosial dan esteem.

\section{Growth}

Kebutuhan yang pada dasarnya tercermin pada keinginan seseorang untuk tumbuh dan berkembang. Kebutuhan ini seperti dijelaskan Maslow diklasifikasikan sebagai aktualisasi diri.

\section{d. Luas Lahan}

Semakin luas lahan pasir pantai yang dimiliki petani akan membuat kebutuhan akan informasi teknologi budidaya bawang merah semakin tinggi guna mencapai efisiensi dan efektivitas sumberdaya yang digunakannya. Hal tersebut membuat petani aktif dalam mencari informasi dan menyampaikan informasi kepada petani maupun pihak lain yang bersangkutan.

\section{Sikap}

Sikap dapat didefinisikan sebagai perasaan, pikiran, dan kecenderungan seseorang yang kurang lebih bersifat permanen mengenai aspekaspek tertentu dalam lingkungannya. Komponenkomponen sikap adalah pengetahuan, perasaanperasaan dan kecenderungan untuk bertindak. Lebih mudahnya, sikap adalah konsekuensi yakni bagaimana seseorang berhadap-hadapan dengan obyek sikap (Van den Ban dan Hawkins, 1999).

Sikap bukanlah pembawaan, dengan kata lain, sikap dapat dibentuk dan diubah sesuai dengan tujuan individu atau faktor- faktor 
yang mempegaruhi sikap tersebut. Pembentukan dan perubahan sikap dapat ditempuh melalui berbagai cara seperti yang dikemukakan oleh W.A Gerungan dalam Santosa (2009):

a. Melalui alat komunikasi, antara lain: surat kabar, radio, televisi, buku, dan lain sebagainya.

b. Faktor-faktor intern dalam pribadi manusia, yaitu kemampuan memilih atau minat perhatiannya untuk menerima dan mengolah pengaruh yang datang dari luar.

\section{Faktor-Faktor yang Mempengaruhi Sikap Petani Terhadap Teknologi Budidaya Bawang Merah}

\section{a. Perilaku Komunikasi}

Sikap seseorang baru diketahui bila ia sudah bertingkah laku. Sikap merupakan salah satu determinan dari tingkah laku, selain motivasi dan norma masyarakat. Oleh karena itu kadangkadang sikap bertentangan dengan tingkah laku (Soelaeman, 1989).

\section{b. Motivasi}

Menurut Siagian (2004), motivasi adalah daya dorong yang mengakibatkan seseorang mau dan rela untuk mengerahkan dalam bentuk keahlian atau keterampilan, tenaga, dan waktunya untuk menyelenggarakan berbagai kegiatan yang menjadi tanggungjawabnya dan menunaikan kewajibannya, dalam rangka pencapaian tujuan dan berbagai sasaran organisasi yang telah ditentukan sebelumnya. Sikap positif akan terbentuk apabila petani memiliki motivasi yang tinggi dalam melakukan budidaya bawang merah. Keinginan untuk memenuhi kebutuhan akan membuat petani terbuka terhadap inovasi dengan sikap yang positif.

\section{c. Pendidikan}

Sikap adalah kencenderungan untuk bertindak akibat adanya rangsangan dari luar. Kecenderungan untuk bertindak ini akan dipengaruhi oleh pengetahuan seseorang. Pengetahuan seseorang dapat dilihat dari tingkat pendidikannya, semakin luas pengetahuan seseorang maka, sikapnya akan cenderung baik (Irmasari, 2013).

d. Luas lahan

Semakin luas lahan yang dimiliki oleh petani, maka sikap petani akan semakin positif karena adanya kecenderungan untuk melakukan kegiatan usahatani yang lebih efektif dan efisien

\section{Adopsi}

Terdapat tahapan-tahapan sebelum masyarakat menerima atau menerapkan suatu teknologi. Mardikanto (2010):

a. Awareness, atau kesadaran, yaitu sasaran mulai sadar tentang adanya inovasi yang ditawarkan oleh penyuluh.

b. Interest, atau tumbuhnya minat yang seringkali ditandai oleh keinginannya untuk bertanya atau untuk mengetahui lebih banyak/jauh tentang segala sesuatu yang berkaitan dengan inovasi yang ditawarkan oleh penyuluh.

c. Evaluation atau penilaian terhadap baik/buruk atau manfaaat inovasi yang telah diketahui informasinya secara lebih lengkap. Pada penilaian ini, masyarakat sasaran tidak hanya melakukan penilaian terhadap aspek teknisnya saja, tetapi juga aspek ekonomi, maupun aspek-aspek sosial budaya, bahkan seringkali juga ditinjau dari aspek politis atau kesesuaiannya dengan kebijakan pembangunan nasional dan regional.

d. Trial atau mencoba dalam skala kecil untuk lebih meyakinkan penilaiannya, sebelum menerapkan untuk skala yang lebih luas lagi.

e. Adoption atau menerima/menerapkan dengan penuh keyakinan berdasarkan penilaian dan uji coba yang telah dilakukan/diamatinya sendiri.

Proses adopsi erat kaitannya dengan pengambilan keputusan. Menurut Rogers (2003) model pengambilan keputusan dalam inovasi meliputi lima tahapan: 
1. Pengetahuan (Knowledge).

2. Persuasi (Persuasion).

3. Keputusan (Decision).

4. Implementasi (Implementation).

5. Konfirmasi (Confirmation).

\section{Faktor-Faktor yang Mempengaruhi Adopsi}

Terdapat beberapa faktor yang diduga berpengaruh dalam proses adopsi, yaitu:

\section{a. Perilaku Komunikasi}

Proses adopsi inovasi individual dalam bidang pertanian tidak bisa lepas dari proses komunikasi pertanian. Berbagai pengalaman menunjukkan betapa kontribusi dari bagian kegiatan komunikasi ini mampu menunjukkan suatu adopsi dari sesuatu hal yang baru (Soekartawi, 1988).

b. Sikap

Sikap positif terhadap pertanian akan mendorong adopsi berbagai macam inovasi. Sikap-sikap baru yang didasarkan pada pengalaman responden atau pemikiran sistematis ternyata lebih memungkinkan membawa perubahan perilaku daripada sikap-sikap yang dangkal. Sikap petani lebih besar kemungkinannya berkaitan dengan perilaku mereka jika mereka telah mencoba sendiri sebuah inovasi atau mengumpulkan informasi mengenai inovasi daripada sekedar mendengarkan pembahasan menarik di radio (Van den Ban dan Hawkins, 1999).

c. Motivasi

Kusumaningrum (2012) dalam penelitiannya mengenai faktor-faktor yang mempengaruhi penerapan budidaya padi menemukan bahwa motivasi berpengaruh nyata terhadap penerapan budidaya padi secara modern. Semakin besar motivasi petani maka semakin tinggi penerapan budidaya tanaman padi secara modern.

d. Luas Lahan

Menurut Lionberger dalam Mardikanto (2009), semakin luas usahatani biasanya semakin cepat mengadopsi, karena memiliki kemampuan ekonomi yang baik.

e. Pendidikan

Menurut Mardikanto dalam Suryadinata (2011), tingkat pendidikan yang telah dimiliki seseorang akan berpengaruh terhadap kapasitas belajar seseorang, karena ada kegiatan belajar yang memerlukan tingkat pengetahuan tertentu untuk dapat memahaminya.

\section{METODE PENELITIAN}

Metode dasar yang digunakan dalam penelitian ini adalah deskriptif. Penelitian deskriptif menggambarkan dan meringkaskan berbagai kondisi, situasi atau berbagai variabel.

Teknik pelaksanaan penelitian ini dengan menggunakan metode survai. Penelitian survei adalah penelitian yang dilakukan pada populasi besar maupun kecil, data yang dipelajari diambil dari populasi tersebut sehingga dapat ditemukan kejadian- kejadian relatif, distribusi dan hubungan antarvariabel, sosiologis maupun psikologis (Wirartha, 2006).

Penelitian ini dilakukan di Kecamatan Sanden Kabupaten Bantul. Kecamatan Sanden merupakan kecamatan yang paling potensial untuk kegiatan budidaya bawang merah di lahan pasir pantai. Sampel yang diambil meliputi sampel desa, sampel kelompok tani, dan sampel petani.

1. Untuk menganalisis tingkat perilaku komunikasi petani dalam budidaya bawang merah di lahan pasir Kecamatan Sanden Kabupaten Bantul dilakukan dengan menggunakan uji proporsi dengan rumus sebagai berikut:

$$
Z_{\text {hit }}=\frac{x / P_{0}}{\sqrt{\frac{P_{0}\left(1-P_{0}\right)}{n}}} \quad, \alpha=10 \%
$$

2. Untuk mengetahui faktor-faktor yang mempengaruhi perilaku komunikasi petani bawang merah di lahan pasir pantai adalah dengan menggunakan analisis linier berganda sehingga didapatkan persamaan regresi sebagai berikut:

$\mathrm{Y}=\mathrm{A}+\mathrm{b}_{1} \mathrm{x}_{1}+\mathrm{b}_{2} \mathrm{x}_{2}+\mathrm{b}_{3} \mathrm{x}_{3}+\mathrm{b}_{4} \mathrm{x}_{4}$ 
Keterangan:

Y : Perilaku komunikasi

A : Nilai konstanta

$\mathrm{b}_{1}, \mathrm{~b}_{2}, \mathrm{~b}_{3}, \mathrm{~b}_{4} \quad$ : Koefisien Regresi

$\mathrm{x}_{1} \quad$ : Kredibilitas media

$\mathrm{x}_{2} \quad$ : Motivasi

$\mathrm{x}_{3} \quad:$ Pendidikan

$\mathrm{x}_{4} \quad$ : Luas Lahan

3. Untuk mengetahui pengaruh perilaku komunikasi dan faktor-faktor lain terhadap sikap digunakan analisis regresi linier berganda sehingga didapatkan persamaan regresi sebagai berikut:

$Y=A+b_{1} x_{1}+b_{2} x_{2}+b_{3} x_{3}+b_{4} x_{4}$

Keterangan:

Y : : Sikap

A : Nilai konstanta

$\mathrm{b}_{1}, \mathrm{~b}_{2}, \mathrm{~b}_{3}, \mathrm{~b}_{4} \quad$ : Koefisien Regresi

$\mathrm{x}_{1} \quad$ : Perilaku komunikasi

$\mathrm{x}_{2} \quad$ : Motivasi

$\mathrm{x}_{3} \quad:$ Pendidikan

$\mathrm{x}_{4} \quad$ : Luas Lahan

4. Untuk mengetahui pengaruh perilaku komunikasi, sikap, dan faktor-faktor lain terhadap adopsi teknologi budidaya bawang merah digunakan analisis regresi linier berganda sehingga didapatkan persamaan regresi sebagai berikut:

$Y=A+b_{1} x_{1}+b_{2} x_{2}+b_{3} x_{3}+b_{4} x_{4}+b_{5} x_{5}$

Keterangan:

Y : Sikap

A : Nilai konstanta

$\mathrm{b}_{1}, \mathrm{~b}_{2}, \mathrm{~b}_{3}, \mathrm{~b}_{4}, \mathrm{~b}_{5}:$ Koefisien Regresi

$\mathrm{x}_{1} \quad$ : Perilaku komunikasi

$\mathrm{x}_{2} \quad$ : Motivasi

$$
\begin{array}{ll}
\mathrm{x}_{3} & : \text { Pendidikan } \\
\mathrm{x}_{4} & : \text { Luas Lahan }
\end{array}
$$

\section{HASIL DAN PEMBAHASAN}

Tinggi rendahnya perilaku komunikasi petani bawang merah di lahan pasir pantai Kecamatan Sanden Kabupaten Bantul dapat diketahui dengan uji proporsi taraf signifikansi $10 \%, \mathrm{x}=15, \mathrm{n}=60$, Po $=50 \%$

$$
\begin{aligned}
& Z_{\text {hit }}=\frac{x / P_{0}}{\sqrt{\frac{P_{0}\left(1-P_{0}\right)}{n}}} \\
& Z_{\text {hit }}=\frac{15 / 60-0,5}{\sqrt{\frac{0,5(1-0,5)}{60}}} \\
& Z_{\text {hit }}=\frac{-0,25}{0,065}=-3,8461
\end{aligned}
$$

Berdasarkan hasil perhitungan menggunakan uji proporsi, diperoleh nilai $\mathrm{Z}$ hitung sebesar -3,8461. Hasil nilai uji proporsi lebih kecil dibandingkan dengan nilai $\mathrm{Z}$ tabel yaitu 1,2815. Hasil tersebut menunjukkan bahwa sebagian besar petani bawang merah di lahan pasir pantai Kecamatan Sanden memiliki tingkat perilaku komunikasi yang rendah.

Untuk mengetahui faktor-faktor yang mempengaruhi perilaku komunikasi petani bawang merah di lahan pasir pantai kecamatan sanden kabupaten bantul digunakan analisis regresi linier berganda metode backward sehingga muncul hasil regresi (Model 5) pada Tabel 1 .

Berdasarkan hasil analisis regresi berganda terhadap faktor-faktor yang diduga mempengaruhi perilaku komunikasi petani bawang merah diketahui bahwa faktor yang

\begin{tabular}{|c|c|c|c|c|}
\hline Variabel & Koefisien Regresi (B) & t hitung & Sig & Ket \\
\hline Kredibilitas media $\left(\mathrm{X}_{1}\right)$ & 0,900 & 15,684 & 0,000 & $*$ \\
\hline Konstanta & $-1,209$ & & 0,223 & $\mathrm{NS}$ \\
\hline R square & 0,809 & & & \\
\hline Adjusted R square & 0,806 & & & \\
\hline F hitung & 245,982 & & & \\
\hline F tabel & 2,794 & & & \\
\hline
\end{tabular}
berpengaruh nyata terhadap perilaku komunikasi petani adalah kredibilitas media. Kredibilitas sumber dan media sangat berperan penting.

Tabel 1. Hasil Analisi Regresi Faktor-Faktor yang Mempengaruhi Perilaku Komunikasi (Model 5)

Keterangan : * signifikansi pada $\alpha=10 \%$

NS Non signifikansi pada $\alpha=10 \%$

Sumber: Analisis Data Primer, 2013 
Komunikan akan mampu menerima informasi yang disampaikan oleh komunikator dan dapat memberikan feedback positif jika komunikator memiliki kredibilitas yang tinggi. Kredibilitas dalam penelitian ini meliputi beberapa unsur, yaitu: kelengkapan informasi, kesesuaian informasi dengan kebutuhan, keaktualan informasi, keakuratan informasi, kemudahan akses, dan kemudahan dipahami. Adanya pengaruh kredibilitas media terhadap perilaku komunikasi petani bawang merah dikarenakan informasi dari media yang disampaikan oleh narasumber yang berkompeten dalam bidangnya, sehingga ketika informasi yang disampaikan lengkap, sesuai dengan kebutuhan, aktual, akurat, mudah diakses, dan mudah dipahami akan meningkatkan tingkat perilaku komunikasi dalam menerima dan menyampaikan informasi melalui media interpersonal, kelompok, maupun media massa karena sudah terbangunnya kepercayaan dalam diri petani.

Untuk mengetahui faktor-faktor yang mempengaruhi sikap dapat dilihat hasil analisis regresi berganda dengan metode Backward (Model 2) pada Tabel 2. mengenai budidaya bawang merah akan terus berkembang.

2. Motivasi

Petani yang memiliki motivasi tinggi dalam budidaya bawang merah lahan pasir pantai cenderung bersikap positif terhadap inovasi. Hal tersebut berkaitan dengan upaya untuk memenuhi kebutuhan dalam hidupnya.

3. Pendidikan

Petani dengan tingkat pendidikan tinggi lebih terbuka akan inovasi dan mendukung setiap adanya inovasi dan perubahanperubahan ke arah yang lebih baik.

Untuk mengetahui pengaruh perilaku komunikasi, sikap, dan faktor lain terhadap adopsi teknologi budidaya bawang merah dapat dilihat hasil analisis regresi berganda dengan metode backward (Model 5) pada Tabel 3.

Berdasarkan hasil analisis regresi berganda terhadap faktor-faktor yang diduga mempengaruhi adopsi teknologi bawang merah di lahan pasir pantai Kecamatan Sanden diketahui bahwa faktor yang berpengaruh nyata terhadap adopsi teknologi bawang merah adalah

Tabel 2. Hasil Analisis Regresi Faktor-Faktor yang Mempengaruhi Sikap (Model 2)

\begin{tabular}{|l|r|r|r|c|}
\hline \multicolumn{1}{|c|}{ Variabel } & \multicolumn{1}{c|}{ Koefisien Regresi $(\beta)$} & \multicolumn{1}{c|}{$\mathrm{t}_{\text {hitung }}$} & \multicolumn{1}{c|}{ Sig. } & Ket \\
\hline Perilaku Komunikasi $\left(\mathrm{X}_{1}\right)$ & 0.246 & 2.037 & 0.046 & $*$ \\
\hline Motivasi $\left(\mathrm{X}_{2}\right)$ & 0.318 & 2.747 & 0.008 & $*$ \\
\hline Pendidikan $\left(\mathrm{X}_{3}\right)$ & 0.204 & 1.685 & 0.098 & $*$ \\
\hline Konstanta & 31.936 & 3.929 & 0.000 & $*$ \\
\hline R Square & 0.295 & & & \\
\hline Adjusted R square & 0.275 & & & \\
\hline F hitung & 7.796 & & & \\
\hline F tabel & 2.184 & & & \\
\hline
\end{tabular}

Keterangan : * signifikansi pada $\alpha=10 \%$

NS Non signifikansi pada $\alpha=10 \%$

Sumber: Analisis Data Primer, 2013

Diketahui bahwa perilaku komunikasi, motivasi, dan pendidikan berpengaruh terhadap sikap petani. Berikut merupakan hasil uji hipotesis untuk setiap faktor yang mempengaruhi sikap petani terhadap teknologi atau inovasi:

\section{Perilaku komunikasi}

Perilaku petani dalam mengakses dan menyampaikan informasi mengenai budidaya bawang merah lahan pasir pantai berpengaruh terhadap sikap petani. Semakin aktif perilaku komunikasi petani, maka pengetahuan petani sikap. Semakin positif sikap petani maka semakin tinggi tingkat adopsi teknologi budidaya bawang merah di lahan pasir pantai Kecamatan Sanden. Tantangan yang dihadapi oleh petani bawang merah di lahan pasir pantai adalah mengenai fluktuasi harga. Jika sedang tinggi, harga bawang merah menembus $\mathrm{Rp} 30.000,00 / \mathrm{kg}$ namun ketika harga sedang jatuh harga bawang merah hanya dalam kisaran $\mathrm{Rp}$ 5.000,00-Rp $7.000,00 / \mathrm{kg}$. Fluktuasi harga tersebut tidak mempengaruhi keberlanjutan budidaya bawang 
Tabel 3. Hasil Analisis Regresi Pengaruh Perilaku Komunikasi, Sikap, dan Faktor Lain terhadap Adopsi (Model 5)

\begin{tabular}{|l|r|r|r|c|}
\hline \multicolumn{1}{|c|}{ Variabel } & Koefisien Regresi $(\beta)$ & \multicolumn{1}{c|}{$\mathrm{t}_{\text {hitung }}$} & \multicolumn{1}{c|}{ Sig. } & Ket \\
\hline Sikap $\left(\mathrm{X}_{1}\right)$ & 0.303 & 2.421 & 0.019 & $*$ \\
\hline Konstanta & 32.718 & 2.188 & 0.033 & $*$ \\
\hline R Square & 0.092 & & & \\
\hline Adjusted R square & 0.076 & & & \\
\hline F hitung & 5.862 & & & \\
\hline F tabel & 2.794 & & & \\
\hline
\end{tabular}

Keterangan : * signifikansi pada $\alpha=10 \%$

Sumber: Analisis Data Primer, 2013

merah oleh petani karena komponen konatif dalam sikap petani cukup tinggi.

\section{KESIMPULAN}

1. Petani bawang merah lahan pasir pantai Kecamatan Sanden Kabupaten Bantul termasuk jarang menerima informasi dan tidak pernah menyampaikan informasi mengenai teknologi budidaya bawang merah tersebut melalui media interpersonal, media massa, dan media kelompok yang digunakan dalam penelitian ini.

2. Sebesar $75 \%$ petani mempunyai tingkat perilaku komunikasi rendah.

3. Faktor yang berpengaruh nyata terhadap perilaku komunikasi adalah kredibilitas media. Semakin tinggi kredibilitas media menurut petani, maka semakin tinggi perilaku komunikasi petani bawang merah.

4. Faktor yang berpengaruh nyata terhadap sikap petani adalah perilaku komunikasi, motivasi, dan pendidikan. Semakin tinggi faktor-faktor tersebut, maka semakin positif sikap petani bawang merah.

5. Faktor yang berpengaruh nyata terhadap adopsi teknologi budidaya bawang merah adalah sikap petani. Semakin positif sikap petani, maka semakin budidaya bawang merah. Meskipun petani aktif dalam menerima maupun menyampaikan informasi, belum tentu membuat petani mengadopsi suatu teknologi. Banyak yang menjadi pertimbangan bagi petani, salah satunya adalah ketersediaan biaya.

6. Perilaku komunikasi tidak secara langsung mempengaruhi adopsi. Perilaku komunikasi akan mempengaruhi sikap petani, kemudian sikap petani mempengaruhi adopsi.

\section{SARAN}

1. Untuk meningkatkan adopsi seyogyanya sikap petani terhadap teknologi diperkuat terutama pada aspek kognitif, yaitu peningkatan pemahaman mengenai pemasaran dan aspek konatif, yaitu mengenai pengairan. Sikap yang positif dapat meningkatkan tingkat adopsi teknologi budidaya bawang merah.

2. Untuk meningkatkan sikap positif petani, seyogyanya perilaku komunikasi petani dalam budidaya bawang merah ditingkatkan dengan cara mengoptimalkan keberadaan media interpersonal, media massa, dan media kelompok yang dapat diakses petani untuk mencari dan menyampaikan tinggi adopsi teknologi budidaya bawang merah.

3. Perilaku komunikasi tidak mempengaruhi adopsi teknologi informasi mengenai budidaya bawang merah.

4. Untuk meningkatkan sikap positif petani terhadap teknologi budidaya bawang merah juga bisa dilakukan dengan memperkuat motivasi petani dalam budidaya bawang merah lahan pasir pantai terutama dengan cara meningkatkan motivasi untuk menjalin hubungan baik dengan penyuluh, pembina Dinas Pertanian, dan peneliti BPTP.

5. Untuk meningkatkan perilaku komunikasi petani, seyogyanya kredibilitas media interpersonal, media massa dan media kelompok yang diakses petani ditingkatkan dengan cara menyediakan informasi budidaya bawang merah yang lebih lengkap, sesuai 
dengan kebutuhan petani, aktual, akurat, mudah dipahami, dan mudah diakses oleh petani.

\section{DAFTAR PUSTAKA}

Anonim. 2008. Kamus Besar Bahasa Indonesia. Pusat Bahasa Departemen Pendidikan Nasional Republik Indonesia.

http://bahasa.kemdiknas.go.id/kbbi/ind ex.php. Diakses tanggal 1 November 2013.

Badan Pusat Statistik Kabupaten Bantul. 2012. Bantul Dalam Angka. BPS. Bantul

Indarwati, Meilani. 2005. Hubungan Antara Perilaku Komunikasi Petani dengan Tingkat Adopsi Teknologi Usahatani Cabai di Kecamatan Pakem Kabupaten Sleman. Skripsi. Fakultas Pertanian UGM.

Irmasari, Rahmatika. 2013. Respons Perangkat Desa Terhadap Penganekaragaman Pangan Tepung Umbi-Umbian di Kabupaten Bantul. Skripsi. Fakultas Pertanian UGM

Kusumaningrum, Arta. 2012. Faktor-Faktor yang Mempengaruhi Penerapan Budidaya Tanaman Padi Secara Modern dan Tradisional di Kecamatan Bayan Kabupaten Purworejo. Skripsi. Fakultas Pertanian UGM.

Mardikanto, Totok. 2010. Komunikasi Pembangunan. UNS Press. Surakarta.

Rogers, M.E. 1995. Diffusion of Innovations.Fourth Edition. The Free Press. New York

Rogers, M.E. 2003. Diffusion of Innovations. Fifth Edition. The Free Press. New York

Santosa, S. 2009. Dinamika Kelompok. Bumi Aksara. Jakarta.

Savolainen, Reijo. 2007. Media credibility and cognitive authority. The case of seeking orienting information. Information Research. http://informationr.net/ir/123/paper319.html. diakses 13 Januari 2014

Siagian, S. P. 2004. Teori Motivasi dan Aplikasinya. Rineka Cipta. Jakarta.

Soekartawi. 1988. Prinsip Dasar Komunikasi Pertanian. UI-Press. Jakarta.
Soelaeman. M. M. 1989. Ilmu Sosial Dasar : Teori dan Konsep Ilmu Sosial. Eresco. Bandung.

Suryadinata, Solichin. 2011. Adopsi Teknologi Ameliorasi Pada Budidaya Bawang Merah di Lahan Pasir Kecamatan Sanden Kabupaten Bantul. Fakultas Pertanian. Universitas Gadjah Mada. Skripsi.

Van den Ban, A. W. dan Hawkins. 1999. Penyuluhan Pertanian. Kanisius. Yogyakarta.

Wirartha, I. M. 2006. Metodologi Penelitian Sosial Ekonomi. Penerbit ANDI. Yogyakarta.

Witjaksono, R. 1990. Hubungan Perilaku Komunikasi dan Tingkat Pemahaman Informasi Anggota Kelompok Tani Tentang Paket Teknologi Supra Insus di WKBPP Sanden, Kabupaten Bantul, D.I. Yogyakarta. Fakultas Pascasarjana IPB. Bogor. 